\title{
Architecture as Symbol and Measure of the Sky in the Ancient and Middle Ages
}

\author{
Manuela Piscitelli* \\ Department of Architecture and Industrial Design, Università degli Studi Della Campania Luigi Vanvitelli, Italy
}

*Corresponding author: Manuela Piscitelli, Department of Architecture and Industrial Design, Università degli Studi Della Campania Luigi Vanvitelli, Via San Lorenzo ad Septimum,Aversa (CE), Italy.

\begin{abstract}
Architectural space is expressed by the union between matter and light, texture and perception, mediated by surfaces, materials, volumes and colours. The relationship between light and space has been known even from the early builders, which in elevating the monoliths have attempted to relate them to the movement of the sun and stars. Architecture was used as a verification tool of these observations, and at the same time for communication and collective celebration of the first major discoveries derived from the observation of nature. Therefore, you can cite numerous examples of architecture built according to specific geometrical relationships associated to astronomical observations. The present study is aimed to put in relation the theorical studies about the representation of light and shadow, the knowledge and the beliefs in the ancient and Middle time with the material characters of architecture. They are analysed examples from the ancient and Middle age to find elements like the orientation of ancient buildings according to cosmic symbols or using of the light to mark the time and the calendar.
\end{abstract}

Keywords: Architecture; Orientation; Geometry; Light rays; Shadow; Cosmic symbols; Archeoastronomy; Solar calendar

\section{Introduction}

The cosmic observation of nature responds to an ancient need of men to understand space and time, which finds its material expression in architecture. It is a need so deep and innate in the human soul, that we can find similar beliefs and symbols in distant peoples without cultural and trade direct exchanges. From the cosmic observation of nature derived geometrical concepts and harmonic relationships common to people of different origins, like the concept of orthogonality and the identification of pure geometric forms, such as the cube or the sphere, associated with specific symbolic meanings. Architecture was used as a tool to verify these observations, and in parallel for communication and collective celebration of the first great discoveries derived from the observation of nature. This is particularly evident in the architectural spaces designed to measure the time through light and orientation. Their design required the knowledge of rules derived from astronomy, drawing, geometry and mathematics. For this reason, the study of geometry and orientation used in architecture to channel the light in the desired way is a useful tool for understanding the theoretical and technical knowledge at the time. The symbolic aspects of geometry materialize through the architecture rites and beliefs related to cosmic observations. Astronomical knowledge in the Mediterranean was applied in architectures intended as a "mirror" of the universe, as they contained in their structure astronomical implications, cosmic miniaturizations, references to Earth, to Heaven and to the movements of the major celestial bodies. The observation of the sun and the shadows projected was also the starting point for the birth of the studies about the projective geometry, the optics and for the creation of instruments for the measurement of time. The use of shadows is also one of the first known methods for the architectural survey. Historical sources report that Thales of Miletus (640-546 B. C.) astonished Egyptians calculating the height of the Great Pyramid using the shadows and the properties of similar triangles, at the time when the sun's rays formed an angle of $45^{\circ}$ with the pyramid base [1].

The present study is aimed to put in relation the theorical studies about the representation of light and shadow, the knowledge and the beliefs in the ancient and Middle time, with the material 
characters of architecture, like the orientation of ancient buildings according to cosmic symbols or using of the light to mark the time and the calendar.

Research in archeoastronomy, intended as a cultural and ethnic astronomy has been burgeoning since the 1980s in cross disciplinary fields, such as anthropology, archeology, history, architecture, astronomy. A wide and recent picture of the state of the art in this research field is the book edited by Clive Ruggles [2]. In recent years, ICOMOS and the International Astronomical Union (IAU) produced jointly two thematic studies, aimed to present an overall vision on astronomical heritage. [3,4]. UNESCO in 2003 begun studies about the astronomical heritage "to establish a link between Science and Culture towards recognition of the monuments and sites connected with astronomical observations dispersed throughout all the geographical regions, not only scientific but also the testimonies of traditional community knowledge" [5]. UNESCO's Astronomy and World Heritage Initiative consider the Cultural heritage related to the sky is a vital component of cultural heritage in general. In 2012 a Portal to the Heritage of Astronomy has been developed in partnership with the World Heritage Centre to support UNESCO's Thematic Initiative "Astronomy and World Heritage" [6]. Since then, many studies have been carried out, with the aim to candidate sites to be included in the astronomical world heritage.

\section{The cosmic harmony in the architecture of the ancient world}

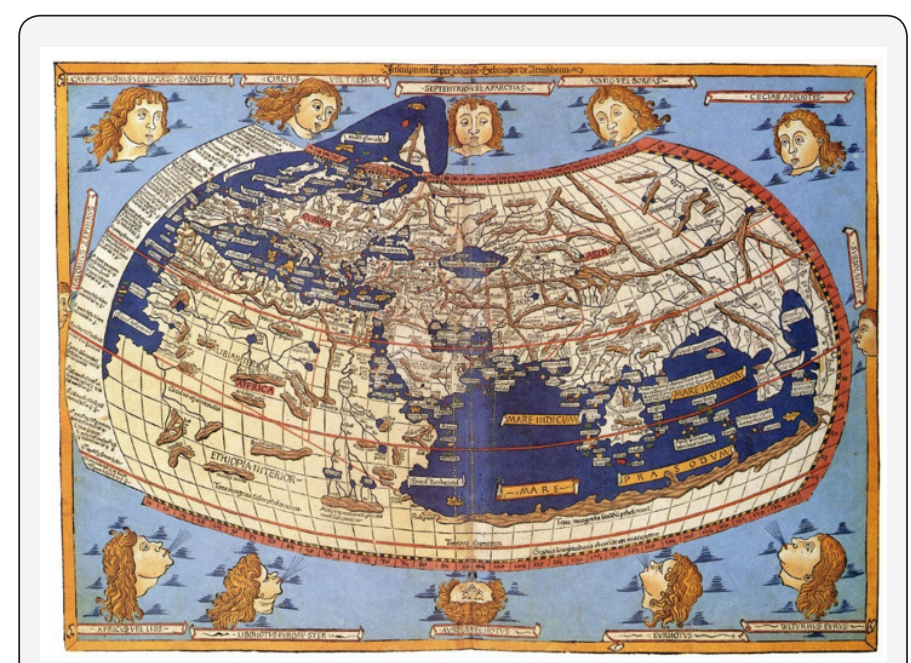

Figure 1: Scenographia systematis mundani Ptolemaici, 1660.

To understand the symbolic meaning attributed by the ancients when they used the effects of light and shadows, and the geometrical methods used for the orientation of buildings to obtain these effects, it is necessary to refer to the way they conceived the world in spatial terms. Unlike today, the space of the ancients was conceived as twodimensional, according to their experience limited to the mobility on one level surface. This conception has heavily influenced, since prehistoric times, the symbolism concerning the relation between the man and the world. In the ancient world were recognized at least eight main directions: the north-south axis, which astronomically connected the culmination of the North Star with the Daily Sun at noon; the east-west axis, that coincides with the points of sunrise and sunset at equinoxes; and the points of rising and setting of the Sun at the two solstices. The entire horizon was analyzed in detail, observing the daily positions of planets and stars. It can be said that the horizon itself became the first giant goniometer in the history, since it was effectively divided into 360 parts (our degrees) just by analogy with the days of the year, suitably rounded [7]. One of the oldest symbols was the circle as a representation of the sky, image derived from the experience of any observer in an open space, who can see around him the sky circumference with an infinite radius [8] (Figure 1).

The next step in the representation of space was to add the third dimension to the two perpendicular axes. The result was the cross with six arms, that is the inclusion of the ground in the symbol of the line perpendicular to the plane, as in the method that we currently use to represent the three-dimensional system of Cartesian axes. This third axis represents the verticality, the ascending and descending movement, but above all the axis of the world, that is an imaginary line joining the zenith and the nadir or connecting the North Star (center of rotation of the universe) with the center of the world, and that continues underground to the astronomical "south pole" [9]. In opposition to the celestial circle, the square was associated with all that is earthly and human, such as cardinal points or even the shape of the houses. From the composition of circle and square, or symbolically from the union between heaven and earth, it derives the octagon, which in addition to be approximately orientate towards the eight main directions, had a marked initiatory symbolism, as it acted as an intermediary between the terrestrial world and the divine one. It is no coincidence that medieval baptisteries had this shape, just to emphasize the function of introducing through baptism into the Christian community. The same references are found in many rituals that accompanied the birth of a new city or the construction of a house. Many ancient peoples, including the Romans, believed that the earth was round and that the sky formed on it a vault or a dome, so the celestial templum should have a circular shape and should be divided into four parts. The reference to the four cardinal points had fundamental importance for the measuring from a conceptual point of view [10]. If very note is the theory of shadows as a codification with geometric rules of the tracing of the shadows produced by a light source, less immediate may appear the possibility of representing geometrically the light. However, one must keep in mind that the possibility of obtaining special effects through the natural light is due to the knowledge of the movement of the sun, and the consequent orientation of the structure and this is essentially a geometrical problem, already known by Greeks and Romans astronomers, that gave the name of analemma to the orthographic projection of the celestial sphere on the horizon. Even Vitruvius, in the ninth book of "De architectura", introduces the construction of a geometric figure, the analemma, that is considered the starting point for the construction of many sundials. The ninth book can be considered a treatise on astronomy, aimed at the construction of sundials [11]. For Vitruvius, the analemma is a rule deduced from the course of the sun and the length of the shadow, beginning with the observation at the winter solstice, which is used as a fixed point. Vitruvius illustrates the geometrical construction, stating that to understand the theory of meridians it is necessary to understand the principle on which the geometrical construction is based. The plane where is drawn the analemma corresponds to the 
plane of the local meridian, so the analemma is a projection on the plane of the meridian circle of the celestial sphere, represented by some main elements, such as the polar axis, the celestial equator corresponding to the equinoxes, the two lines of the Tropic of Cancer and the Tropic of Capricorn, the projection of the circles in which moves the sun at the solstices (Figure 2).

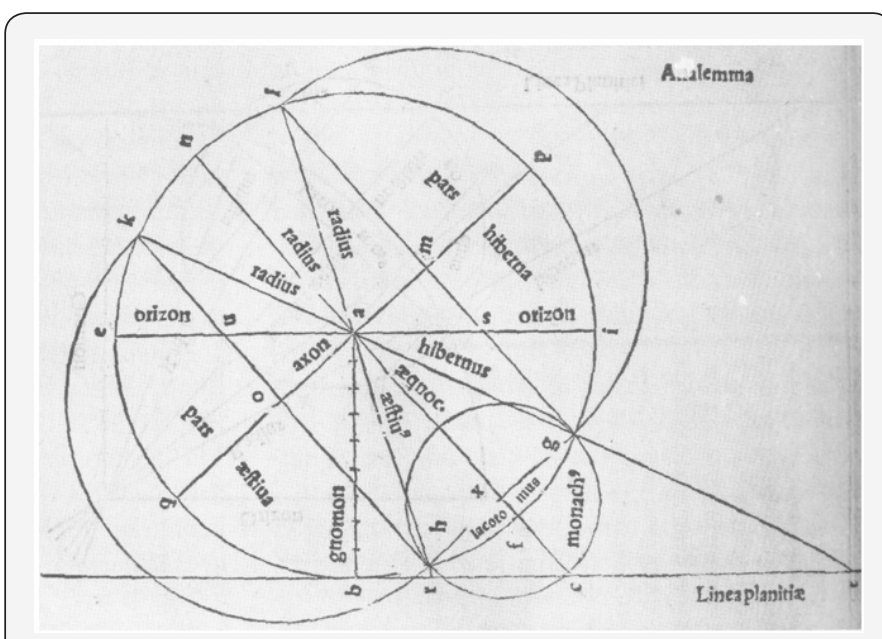

Figure 2: Vitruvius analemma. From: Fra Giocondo, M. Vitruvius per locundum..., Venice 1511.

At the time of Ptolemy, the representation of the sphere in orthographic projection has been a big step for the astronomy of position, setting the stage for encoding descriptive geometry and perspective. It was used in the construction of solar watches, where the planes of the sphere parallel to the horizon are overturned on the plane of the dial with a projection from the center of the analemma. This projection is called gnomonic, namely from the center of the sphere pass all the lines from the surface of the sphere to the plane of the dial. The gnomon was the first instrument in ancient times that made it possible" given the exact point where you are located, measuring the time" [11]. It consists of an indicator, often a vertical stake, which projecting its shadow on a horizontal dipstick allows to know exactly not only the time but also the solar transit and the movement of the earth around it. The analemma is convenient to check the height of the sun transit at any time of the day, projecting the plane of the sun on the horizon. We can therefore understand how the knowledge of this graphic construction is fundamentally important if you want to place a hole to channel the light in a day of the year, for example to mark a holiday. The geometric procedure to orient a building through the shadows was very simple: it was planted a stick on the ground, making sure it was perfectly vertical, and from its base was traced a circle around it. In the morning they expected that the shadow of the gnomon went exactly to hit a point on the circle; in the afternoon this procedure was repeated with a second point. The segment that connected the two points indicated the east-west axis. Finally, they traced a perpendicular to this line, passing through the base of the stick, to obtain the north-south axis. The procedure was based on the observation that the sun casts the same shadow twice a day, once in the morning and another in the afternoon, and the axis of symmetry between the two lines is exactly the North/South axis [12]. The path of the sun across the sky was well known, having been studied by men since ancient times, even before the development of agriculture, probably for reasons related to survival, such as the management of the food stocks for the winter, that required to know the exact end of the cold period. The knowledge of the course of the sun, due to these observations since ancient times, created a baggage of knowledge that, in addition to being used in the orientation of buildings, has allowed the development of different types of instruments for determination of time. The key moments of the year were obviously those that marked the beginning of the four seasons: the annual cycle in fact see the sun every day along an arc in the daytime sky, always different from the one of the previous days and the one of the next days. The "growing" phase begins at the winter solstice, the day on which the sun runs its lowest arc, rising in the south-east and setting in the south-west. It continues during the months of January and February, until it reaches the "balance point" on the spring equinox, when the hours of daylight and darkness are perfectly equal, and the sun rises and sets exactly on the east-west axis. From this moment the daylight hours prevail over the night, until the sun reaches its highest point in the summer solstice, with sunrise in the north-east and sunset in the northwest. On this day the sun reaches its highest point at noon. After the solstice, the days begin to shorten and at the autumn equinox the sun returns to a situation specular to the spring one. In the ancient Egypt, the Pharaoh had the duty to determine the orientation of a temple or a pyramid, and it was performed according to a ritual character. For example, the pyramid of Cheops, in the valley of Giza, is perfectly aligned with the four cardinal points. An experiment in 1853 showed that it would be easy for ancient Egyptians to use the pyramid of Cheops to calculate equinoxes, if they had observed the sunrise and sunset from the top of the pyramid [13].

The passage that crosses from north to south the funerary chamber inside the pyramid was built with an angle exactly corresponding to the latitude of the pyramid itself, and the corridor runs parallel to the axis of the Earth. Thereby, the pyramid contained all directions needed to perform astronomical measurements, although it can be assumed that these orientations primarily had a symbolical value. Moreover, in the temples Egyptians used to realize light wells to channel the sun's rays to specific points, reinforcing the symbolic meaning of the religious building: for example, in the temple of Abu Simbel, thanks to the alignment of the doors, which took account of the inclination of the sun in relation to the earth's axis, twice a year, on February $21^{\text {st }}$, day of birth of Ramses II, and on October $21^{\text {st }}$, the day of his coronation, the first ray of the sun focused on the face of the statue of the Pharaoh. The rays of light also partially illuminated the statues of Amon-Ra and Ra-Harakhti. According to the ancient Egyptians, the sun's rays would thus recharge with energy the figure of Pharaoh, while the god Ptah, considered god of darkness, was never lit.

In the Mediterranean, between North Africa and Spain, during the Bronze Age they frequently constructed funerary monuments oriented towards the points of the sky where the sun rises or sets. Even the nuraghe in Sardinia have a cosmic orientation, so that almost all the complex nuraghe have one, or more than one, of the tangent lines to the peripheral towers oriented towards one of the points where the sun and the moon rise or set at the solstices [14]. The morning sun, on the day of the winter solstice, enters a window illuminating a stone. The entrance of a sunbeam in the nuraghe is technically possible thanks to a deviation of the 
wall at the entrance, that allows to capture the light orthogonally. Cosmic observation in the ancient world also led to quantitative interpretations, or the definition of Numbers, units of measurement which, starting from the philosophical theories of Pythagoras and Plato, influenced architectural theory and practice for centuries. The Greek philosophy, since its origins, invited to look at the sky to imitate its order, also because, according to Pythagoras and Anaxagoras, there was nothing that gave more happiness than the spectacle of the starry sky with its regular, perpetual, cyclical return of planets and stars. To imitate this cosmic order would mean to transfer to the earth the admirable harmony between its parts, through the re-proposition of numerical relationships. In the Greek world, in fact, the notion of number was a sort of imprint of divine thought, a memory of creation that is hidden in the nature and can be reproduced applying the harmonic rules in architecture. Romans has been the first to appreciate the architectural space using light. During the imperial age they used sophisticated systems for capturing the light and direct it, encoding cuts in the shell, as the perforation of the vaults and the creation of rays of light. In this way, it was enhanced the quality of the overhead light, intended as a material of the interior spatial design. Moreover, since the time of Augustus, the so-called solar machines were part of the iconography of the imperial power, as the emperor, in the role of Pontifex Maximus, superintended the calendar and consequently the rites and ceremonies related to the cycle of the time and the changing of the seasons [15] (Figure 3).

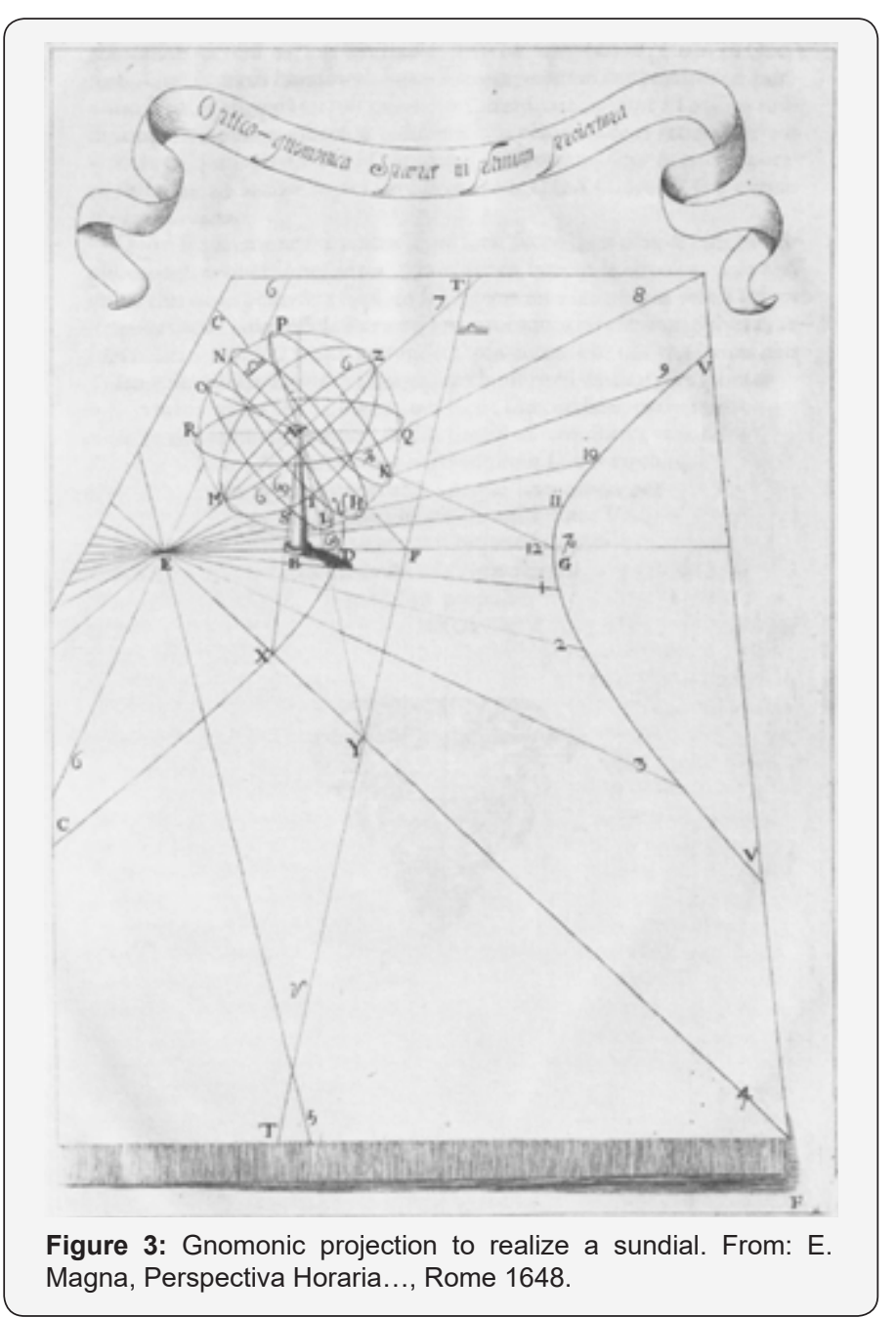

The gnomon, with its technological simplicity, since ancient times allowed to study the two apparent motions of the Sun, the daily and the annual, respectively due to real motions of rotation and revolution of the Earth. Many ancient peoples used the sundials; the largest exemplum was the Horologium Augusti in the Campus Martius area, in front of the Ara Pacis in Rome. Realized by the Emperor Augustus, the monument consisted of a large square paved in travertine, on which were traced by strips of bronze the indications of hours and perhaps the parabolic arches of the analemma. Its gnomon was a large Egyptian obelisk of red granite, about 30 meters height, taken from the city of Heliopolis in Egypt. The obelisk was transported with great difficulties by sea and then along the Tevere river, in a journey that lasted about two years. Landed at the Forum Boarium, the monolith was dragged to its location in the Campus Martius to be raised into position [16]. On top of the obelisk towered a tipped sphere, which reached a height of one hundred Roman feet, corresponding to 29.5 meters. The shadow of the sphere, projected on the dial, indicated the time, the day and the month. In addition, on the sunset of September 23rd, on the day and hour of the birth of Augustus, the shadow descended on the Ara Pacis as an homage to the emperor [17]. The sundial, created by the mathematician Facundus Novius, has been used only for half a century because, as Pliny writes, it collapsed in an earthquake and for the flooding of the Tiber, which deposited large layers of mud on the plates of the dial. The sundial was an instrument rather common, so that in the ninth book of de Architectura Vitruvius lists no less than 13 different types of sundials. What is unique about the Horologium Augusti than the other astronomical instruments in Rome, besides the dimension, is its capacity to operate with precision as calendar. Three years before its realization, Augustus had inherited from Lepidus the office of Pontifex Maximus, and among the duties of the magistrate there was to supervise the calendar. In this role Ottaviano corrected the reform of the calendar carried out by Julius Caesar, that had been applied incorrectly.

\section{The cosmic symbols in the architecture of the middle ages}

The habit to build a church following celestial axes is the logic consequence of the adoption of a liturgical year based on the calendar used by the Romans. The man of ancient times, as well as the man of the Middle Ages, did not separate time division from space division, since time measurement was based on the movement of celestial bodies, which can only be calculated through the observation of their immutable trajectories. Nevertheless, if today mechanical instruments for time measurement are available - so that the mutual relation between time and space is for us an abstract concept requiring some representation efforts. The ancients, who did not consider either time or space from a merely quantitative point of view, perceived this mutual relation as an immediate observation [18]. However, the orientation of the churches, and the subsequent use of light inside, is also related to spiritual considerations, to the will to reproduce on Earth the source of life symbolized by light source. According to Burckhardt, in a spiritual perspective, the sanctuary was always located in the center of the world, and thereby makes it a sacratum in the true sense of the term: a place where man is subtracted from the 
indefinite space and time, since 'here' and 'now' God is present in man. This concept is expressed by the shape of the temple: indicating the cardinal points, the shape orders the space in relation to its center. It is the synthesis of the world: thing that in the universe are in constant motion, in the sacred architecture are transposed into a permanent form. In the cosmos, the time dominates the space; in contrast, in the construction of the temple, somehow it happens that the time is turned into space: the great rhythms of the visible cosmos, symbolizing the main aspects of existence disjointed and dispersed, are assembled and fixed in the geometry of the building [19]. The Christian Church is the Church of the Incarnation, so the whole symbolism summarizes the meaning of the Incarnation of the Word, visible image of the invisible God. The rules of construction come from God himself who is the real architect, while the builders imitate God executing his project. This assumption is crucial in medieval times, to the point that the Romanic church was not signed because through the anonymity the architect did homage to the great builder of the temple built with the men living stones.

The connection between theology and architecture at this time was very close: as theology was intended to make clear the foundation of faith, so the architecture, the Romanic churches of the thirteenth century, became the instrument for the collective education of the people and their participation in the revealed Truth. The first fundamental symbol was the orientatio. The church stood in a sacred space, separate from the profane space by a fence and the cosmic orientation. The church was oriented following two directions: toward the light or the sunrise, and upwards, toward the North Star. The longitudinal axis or solar axis was directed to east, symbol of the light and the victory of Christ over the darkness, while the vertical axis, named axis mundi, connected the temple to the polar star orienting the church upwards, to connect the sky, the earth and the underworld. Carrying out the orientation, it should be considered that every day the sun changes its point of sunrise and sunset over the astronomical local horizon, reaching its minimum and maximum peak at the equinoxes and solstices. The orientation to the east in Christian churches was usually determined by the sunrise at the equinoxes, while for example in the Longboard churches it was preferred to align the nave to the sunrise at the solstice, according to a legacy of pagan cult. The orientation was also useful to determine the time of day and the moments of prayer during the day to be made in the canonical hours. With these references, it was possible to verify the flow of time, both observing the flow of light and shadows on the external walls on sunny days, either according to the beams of light projected through the oriented openings, - even when the external light was poor and the sky cloudy - inside the church usually quite dark. Inside the church, the beams illuminated landmarks, usually drawn in the altar for the light coming from the windows of the apse, and on the floor, in the barycenter of the church, for the illumination through the windows of the nave. Unfortunately, today in most cases it is difficult to reconstruct this relationship between the iconographic reference points and the orientation of the openings, since following the dictates of Liturgical Reforms, the composition and position of the vestments inside the liturgical churches has been radically and repeatedly changed since the Middle Ages.
From the constructive point of view, the cosmic symbolism of the church was also realized according to precise criteria for the proportions of the various parts of the building. In this case, they referred to the mystical significance that the tradition attributed to geometrical figures; for example, great importance was attributed to the decagon figure. It is well known that the proportions of a church generally resulted from the harmonic division of a large circle for five or ten. Such Pythagorean method, which Christians architects had probably inherited from the collegia fabrorum, was applied not only on the horizontal plane, but also along a vertical plane, so that the building was inscribed in an imaginary sphere: a symbol well-rich and very suitable for the purpose that it was proposed [19]. Again, from the point of view of geometrical symbolism, it was crucial the dialogue between circle and square, which summarized the relationship between man and God. The circle symbolizes the sky, the sacred, the spiritual world, while the square represents the cosmos, the matter, the earthly condition. For centuries the archetypal form of the Byzantine church consisted of a cube surmounted by a dome; Hagia Sophia in Constantinople was its prototype. In the Timaeus, Plato commends the sphere as an image of the cosmos, and he gives to each of the "cosmic figures" a symbolic meaning. The last was the dodecahedron, composed of twelve pentagonal faces, that is the cosmic symbol par excellence. About it, Plato writes "remained a fifth combination, and God used it to decorate the universe". In the Romanic space, apse and dome were circular, as dedicated to God, while the nave, realized for his people, was rectangular. God and man, spirit and matter met in the sacred time and the terrestrial space of the temple and liturgy. The apse of the medieval church, with its concave geometry surmounted by a shell, which is nothing more than a quarter of a sphere, postponed the ancient image of the sky and the celestial spheres, and can be considered a symbolic door to access the sky. During the Middle Ages, the edification of a church was subjected to very precise rules, not only about the orientation of its axis entranceapse, but also about the period when the rite of foundation should be celebrated. Guido Bonatti from Forlì, mathematician, astronomer and astrologer who worked in Paris during the thirteenth century, in his "Tractatus Decem Continens astronomiae", highlights that the churches, as centers of divine power, had to be raised following precise ritual rules according to the cosmic course, and had to be built when they occur certain favorable astral conjunctions [20].

The churches had to acquit to the liturgy; therefore, in the design phase the architects received precise instructions, based on a complex set of guidelines taken from the liturgical symbolism of the Christian religion. The architect had the task to use mathematics, geometry, and astronomy to express symbolically the liturgical function of the cult. The geometrical symbols can be found not only in the orientation, but also in the overall design of the plan, including individual elements, such as the altar or the portal. Entering the temple, you came in the mystery of creation and salvation, as the portal had a strong symbolic value as access to the axis mundi, the cosmic path where the heavenly mystery descended in the temple. The portal summarized in geometrical terms the plan of the building: the rectangle of the panels reproduced the nave, while the lunette above repeated the circular shape of the apse (Figure 4). 


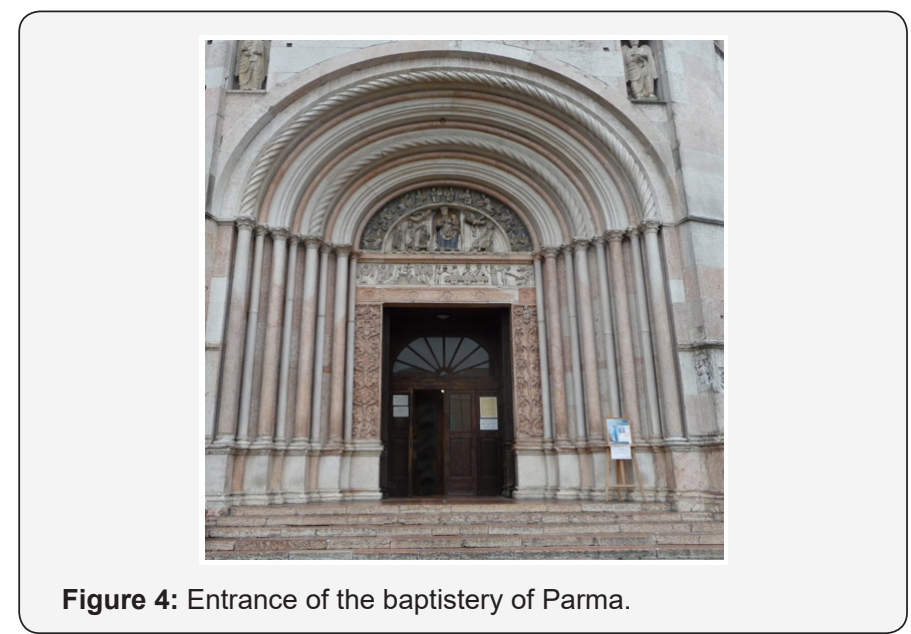

People passed through the square of the doors, while the semicircular tympanum, like the apse of the dome, hosted the Blessing Christ in glory. After crossing the threshold, on the via salutis - initiatory path leading from the threshold of the temple to the altar -, the Christian entered the temple through the portal on the west, and from the darkness of the west gradually approached to the light of the sun shining in the altar on the east [21]. If the church was the center of the universe, the altar was the center of the church. The steps usually leading to the altar remembered the ascent of the temple of Jerusalem, the holy mountain on which it was built. The altar was the microcosm where was concentrated the mundus, the entire creation; the liturgy that took place on the altar under the Christ Pantocrator (Creator of the Universe) reflected the heavenly liturgy of the genesis [9]. About the importance of the orientation of medieval buildings, it is finally to underline the clear relationship with the iconography sculptured and painted in the buildings themselves. It is a varied and imaginative iconography in which there are some recurring symbols, often in association with one another. Some have a "solstitial" cosmic value, as the "Celtic circle", or "equinoctial" as the eight-pointed star inserted in a circle, derived from an ancient iconography of the planet Venus; or symbolize the sunshine like the lily or cornflower. As an instrument to regulate the calendar, a properly oriented building was able to make immediately perceivable the beginning of the year and its most significant moments, especially referring to the solar calendar. This phenomenon is particularly evident in the medieval churches. Since the early Christian age, the figure of Christ was in fact associated with the Sun and the light, in the wake of the late Roman solar cults (Figure 4). It is known that the orientation of the apse was generally directed ad solem orientem, that is the East, where the sun rose at sunrise in the two equinoxes or in the date of special liturgical festivity, like the festivity of the saint whom the church was dedicated. This practice is a proof of the deep root of solar symbolism in the medieval liturgical architecture [22]. In the construction of a church was not uncommon to go beyond the simple east-west orientation, and set the whole plan of the building according to the annual movements of the Sun. The basic geometrical shape was the so-called "Polygon of God", the decagon inscribed in a circle, which invokes the symbolism of the number ten, symbol of perfection, wholeness and at the same time of "return to unity" [23] (Figure 5).

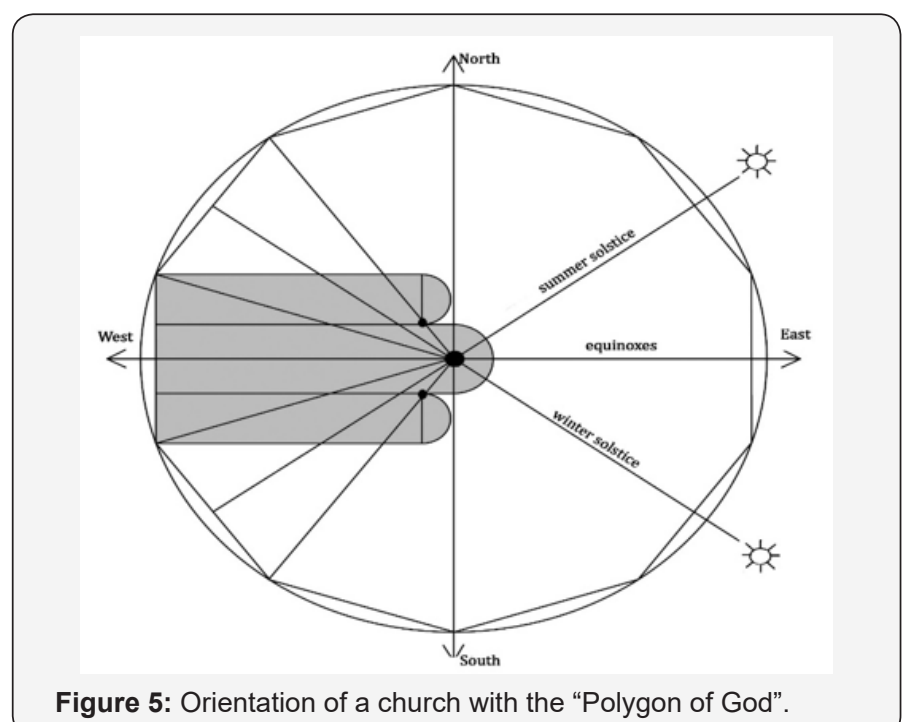

The alignment of a church to the solar motion was carried out following the rules of geometry. For example, using a grid construction consisting of squares and golden rectangles, you can find with good approximation, limited to at our latitude, the position of the sun, intended as its angular height at noon on the solstices and equinoxes. The use of sunlight in the churches, in addition to recall this symbolism, also had a calendar function. The medieval religious sites were designed as giant sundials that marked the time of the liturgy on the various days of the year. During the year, the light marked different parts of the church, illuminating every time the frescoes of the saint of the day or the festivity to celebrate. A useful aid for clergy and a wonder for the faithful. In the Romanic architecture can be found churches apparently ungainly and nonsymmetrical, because of the need to be orientated with moments of the path of the Sun. One example is the windows offaxis from the line of symmetry of the facade, as oriented to channel light at certain times of the year, usually the sunrise or sunset of a festivity. The will to use the light rays to describe the cyclic values of time on sacral or seasonal religious feast-days, is expressed at the highest level in certain Croatian architectures of the Early Middle Ages, carefully studied by Mladen Pejakovic. In the church of Santa Croce at Nona, the external walls are oriented following the directions of sunrays over the local horizon in the morning, at noon and in the evening. The windows are asymmetrically arranged, and their opening is strained to allow the projection of the rays in certain points inside. The cross-shaped architecture is intentionally strained by the will to make the structure corresponding to a series of astronomical data, thus turning it into a kind of stone calendar oriented according to the geo-astronomic local conditions [24]. Similarly, the church of the Santa Trinità at Poljud (Split), is strained to adjust it to sun inclination angles over the local horizon. The windows of the apse are arranged following the local east, so that the first sunray appearing on seventh May, San Doimo day, would be perpendicular to the step of the presbytery. The windows of the side apses are not located at the center but are cut in the wall to allow the passage of the light beam. A series of other light peculiarities planned for certain days of the liturgical year, such as Christmas or Saint John Day, contributed in making the church like a measuring instrument, by which the faithful could recognize the rhythms of the 
sacred time scanned by the sun course. Such astronomic references can be also found also in other kind of buildings. An emblematic example is Castel del Monte, a building completely imbued with astronomical, geometrical, and mathematical implications, that in their whole language make the monument one of the greatest stages reached by the technique in the age of Frederick II. The links between the construction of Castel Del Monte and the geometrical and astronomical culture at the time, have been subject of several studies that revealed a set of correspondences; first the orientation to the east of the entrance wall, related to the sun rising at equinoxes.

Castel del Monte has an octagonal shape; at each corner is inserted an octagonal tower. The courtyard has the same shape, with eight rooms on the ground floor and eight on the top floor, all trapezoidal and equal. The spatial distribution of these architectural elements obeys to precise indications related to the Sun position during the year. The courtyard, the rooms and the external octagonal walls, are marked from real and theoretical shadows of the sun at his entry into the zodiacal signs. In addition, the castle latitude and the value of the sun culmination at the equinox, are enclosed within the triangle formed by the height of the courtyard south wall, the width of the court itself, and the ideal hypotenuse joining them. Only at this latitude, the points on the horizon where the sun rises and sets at the solstices, ideally joined, describe a golden rectangle in the center of which the castle is located. In addition, the golden proportion is widely used in the sizing of the structure and details, as the entrance portal [25]. Once a year, at autumn solstice, the shadow of the walls at noon covers all the other parts of the castle. At that time, the walls cast a shadow on the ground with the same length of the courtyard of the castle. In the following days, the shadow lengthens reaching the length of the rooms and finally the ideal circumference where the castle is inscribed. The sheet of water enclosed in the octagon of the marble basin, that once adorned the center of the courtyard, recalls oriental solutions. The octagon shape is developed in subsequent reductions from the drawing of the edge to the internal seats, reproducing the architecture geometry, but at the same time reflecting the sky, to establish a direct relationship between architecture and nature [26-29] (Figure 6).

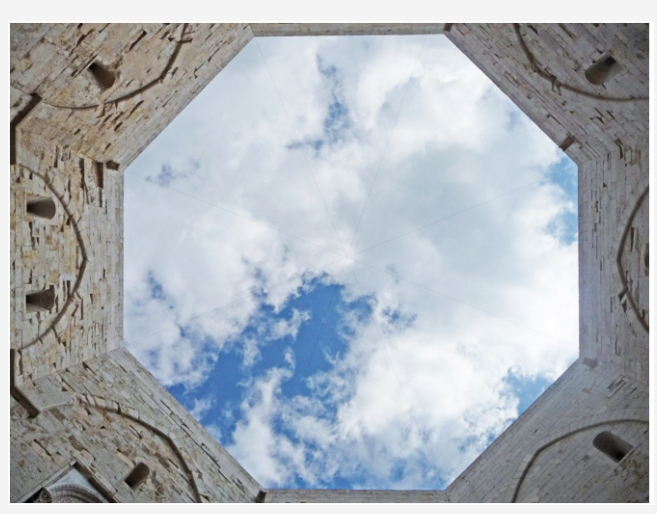

Figure 6: Castel del Monte, courtyard.

\section{Conclusion}

Modern science has increasingly distanced itself from the idea of cosmic harmony made up of pure forms, replacing it with the idea of a fragmented universe, rich in differences, and of a complex and multiform nature. However, the theme of light and shadow in architecture still has a special fascination for the deep symbolic meanings related since ancient times to the desire to reproduce on earth the harmony and the perfection of the universe. The study of examples from the ancient and Middle ages demonstrate the existence of a strong relationship between the geometrical composition of architecture, the astronomical references, the symbolic and philosophical values, the cultural tissue where the examples are inserted. A great importance is given to the symbolic aspects of geometry, which materialize through the architecture rites and beliefs related to cosmic observations. These aspects, which may seem outdated today, have nevertheless become a repertoire of archetypes that continue to be used by contemporary architects, and still make the man fell as a part of the universe.

\section{References}

1. Higgins PM (2002) Un mondo di matematica. Dalle piramidi egizie alle meraviglie dell'Alhambra. Dedalo.

2. Ruggles C (2014) Handbook of Archaeoastronomy and Ethnoastronomy. Springer, London.

3. ICOMOS IAU (2010) Heritage Sites of Astronomy and Archaeoastronomy in the context of the World Heritage Convention A Thematic Study. ICOMOS-IAU, Paris, France.

4. ICOMOS IAU (2017) Heritage Sites of Astronomy and Archaeoastronomy in the Context of the UNESCO World Heritage Convention Thematic Study. Vol 2, Ocarina Books Ltd, UK.

5. UNESCO (2012) Official web page of the Astronomy and World Heritage Initiative.

6. Ruggles, Clives (2012) Astronomy and World Heritage. In: Ian Corbett (ed.), Reports on Astronomy. IAU Transactions 28A. Cambridge University Press, Cambridge, USA, pp. 405-407.

7. Biémont E (2002) Ritmi del tempo Astronomia e calendari. Zanichelli, Italy.

8. Guénon R (2004) Symbols of Sacred Science. Sophia Perennis.

9. Hani J (2007) The Symbolism of the Christian Temple. Sophia perennis.

10. Rykwert J (1976) The idea of a town: The Anthropology of Urban Form in Rome, Italy, and The Ancient World. Faber \& Faber.

11. Ronca L (1976) Gnomonica della sfera e analemma di Vitruvio. Roma, Accademia dei Lincei.

12. Bartolini S (2006) I fori gnomonici di Egnazio Danti in Santa Maria Novella. Polistampa, Florence, Italy.

13. Biot JB (1855) Determination de l'equinoxe vernal de 1853, Astronomie égiptienne, Paris, France.

14. Zedda MP (2002) Per una Sistematica Classificazione della Torri Nuragiche. Sardegna Antica C.M, Nuoro.

15. Ball LF (2003) The Domus Aurea and the Roman architectural revolution. Cambridge: Cambridge University Press.

16. Plinio the Old, Naturalis Historia. XXXVI, 72 ss.

17. Rendina C (2007) L'orologio solare di Campo Marzio. La Repubblica Roma.

18. Coomaraswamy AK (1935) Medioeval aesthetic The Art Bulletin. vol. XVII, n. 1.

19. Burckhardt T (2001) Sacred Art in East and West. Fons vitae.

20. Bonatti G (1491) Liber astronomicus decem continens tractatus astronomiae. Erhard Ratdolt Publisher.

21. Rusconi C (1996) Tempus Templum. Faenza, Italy. 
22. Di Bennardo A (2005) Pietre orientate Roma. Meltemi, UK.

23. Feuillet M (2007) Lessico dei simboli cristiani. Edizioni Arkeios, Italy.

24. Pejakovic M (1982) Le pietre e il sole Architettura e astronomia nell'alto medioevo proto-romanico croato. Jaka Book, Milano.

25. Tavolato A (1991) Astronomia e geometria nella architettura di Castel Del Monte. Laterza.
26. Hautecoeur L (2006) Mistica e architettura. Il simbolismo del cerchio e della cupola. Torino: Bollati Borighieri.

27. Michell J (1988) The dimensions of Paradise. Thames and Hudson, London.

28. Mollet J (1837) Gnomonique Graphique. Paris, France.

29. whc.unesco.org/en/astronomy 